\title{
Getting better or getting worse? Consumer responses to decreasing, constant, and ascending multi-dimensional price profiles
}

\author{
Klaus Peine $\cdot$ Daniel Wentzel $\cdot$ Andreas Herrmann
}

Received: 25 October 2009/Accepted: 2 August 2010/Published online: 20 October 2010

(C) Springer-Verlag 2010

\begin{abstract}
This research investigates consumer preferences for different multidimensional price profiles. Drawing on research on price affect, we investigate whether consumers prefer descending monthly installments (e.g., 40, 30, 20, 10) over constant (e.g., 25, 25, 25, 25), or ascending ones (e.g., 10, 20, 30, 40). Results of a field experiment with a sample of 1,628 German car buyers corroborate the hypothesized profile effect. In the experiment, participants were asked to evaluate different finance offers for a new car that all had the same present value but differed in terms of how the installments unfolded over time. Consistent with the hypotheses, decreasing monthly installments are evaluated more favorably than constant installments, which, in turn are evaluated more favorably than ascending installments. Furthermore, the results provide evidence for the underlying process by showing that the impact of different MDP profiles is mediated by positive affect. Finally, it was hypothesized that consumers' individual differences (i.e., debt aversion, financial expectations, and product category knowledge) would exert a moderating influence on evaluations of different price profiles; these hypotheses, however, were only partially confirmed. Theoretical and managerial implications are discussed.
\end{abstract}

Keywords Multi-dimensional pricing - Evaluations of sequential outcomes · Intertemporal choice · Appraisal theory

\footnotetext{
K. Peine

Bain \& Company, Rothbuchstrasse 46, 8037 Zurich, Switzerland

e-mail: klaus.peine@bain.com

D. Wentzel · A. Herrmann $(\bowtie)$

University of St. Gallen, Bahnhofstr. 8, 9000 St. Gallen, Switzerland

e-mail: andreas.herrmann@unisg.ch

D. Wentzel

e-mail: daniel.wentzel@unisg.ch
} 


\title{
Mathematics Subject Classification (2000) $62 \mathrm{~K} 15$
}

\author{
JEL Classification M31 $\cdot$ M37
}

In multi-dimensional pricing, companies communicate prices to consumers using more than a single number (Estelami 1997; Morwitz et al. 1998; Kim and Kramer 2006). While uni-dimensional prices simply consist of a lump-sum amount (e.g., $€$ 37,125), multi-dimensional prices (MDPs) are quoted in terms of several price attributes. These include monthly installments, repayment period, or downpayment (e.g., $€ 836$ a month for 48 months, $€ 0$ down). In recent years, the propensity to finance consumption has increased consumers' exposure to MDPs. For a variety of product categories-e.g., household appliances, telecommunication services, and cars-MDPs have even become the dominant form of price quotation (Estelami 1997).

Research on disaggregated prices has demonstrated that moving from unidimensional to multi-dimensional price presentations may lead to a substantial increase in demand (Gourville 1998; Morwitz et al. 1998). Consumers may be affected by how prices are communicated because they are usually unable or unwilling to evaluate complex price information in an accurate manner (Estelami 1997; Morwitz et al. 1998). That is, consumers-rather than computing the true value of MDPs-may rely on heuristics in order to simplify their decision-making process (Kahneman et al. 1982). However, the current literature has not fully examined which heuristics consumers rely on for evaluating MDPs.

One prominent, easy-to-use heuristic may be based on the sequence in which installments unfold over time. As such, MDPs usually rely on installments that remain constant over the repayment period (e.g., 25, 25, 25, 25). However, managers may also frame MDP profiles in terms of increasing installments (e.g., 10, $20,30,40$ ) or decreasing installments (e.g., 40, 30, 20, 10), without altering the net value of the payment. While modifying MDPs profiles in this manner may be very easy to implement, existing research has not investigated how consumers respond to MDP profiles with different sequences.

In this research, we address this important gap in the literature and examine if consumers respond more favorably to ascending (e.g., 10, 20, 30, 40), constant (e.g., 25, 25, 25, 25), or descending installments (e.g., 40, 30, 20, 10). To this end, we develop a conceptual framework that is based on recent research on the affective consequences of price information (e.g., O'Neill and Lambert 2001; Peine et al. 2009). This stream of research proposes that consumers' reactions to price information are not only determined by their cognitive assessments, but also by the information's emotional implications. In a similar vein, we propose that consumers' evaluations of different MDPs profiles are also determined by the affect they experience while processing the profiles. More specifically, we argue that consumers will experience greater affect and will show more positive evaluations when the MDP profile is framed as a series of outcomes that improve over time compared to when they remain unchanged or deteriorate over time. 


\section{Conceptual development}

\subsection{The influence of price affect on consumer behavior}

In recent years, scholars have noted that most pricing research is cognitively biased (e.g., O'Neill and Lambert 2001; Peine et al. 2009; Suri et al. 2002). That is, most research focuses on cognitive price-related phenomena (e.g., reference prices, pricequality inferences, price fairness perceptions) and has neglected consumers' affective reactions when processing price information. This lack of research is somewhat surprising since affect has been shown to be an important antecedent of consumers' reactions to marketing offers (Andrade 2005; Bagozzi et al. 1999; Frijda 1986; Ladhari 2007). For instance, imagine a consumer who faces severe budget constraints and who finds that her favorite shampoo has just become more expensive. Regardless of whether she can still afford the shampoo or not, the price increase is likely to evoke a negative emotional reaction (e.g., anger, despair) that may affect her purchase decision. In a similar vein, a price decrease may alleviate the consumer's budget constraints and may therefore elicit a positive affective response (e.g., relief).

Despite the potential relevance of affect in consumers' price evaluations, most research has remained relatively silent on this issue. Recently, Peine et al. (2009) have examined the role of price affect in terms of appraisal theory. Appraisal theory (Lazarus 1991a, b) posits that people appraise the events in their environment in terms of the consequences for their psychological and physical well-being. This implies that affect arises from the cognitive appraisal of an event rather than from the event itself (Lazarus 1991a, b; Roseman et al. 1990). As such, individuals evaluate whether a particular event has beneficial or harmful implications for their current goals, concerns, and aspirations. Events that are judged as beneficial will give rise to positive emotions (e.g., hope, joy), whereas events that are considered as harmful will engender negative emotions (e.g., anger, despair) (Roseman et al. 1990).

Appraisal theory may also help in explaining consumers' affective responses to price information. From a consumer perspective, price reflects the monetary sacrifice one has to make in order to acquire a certain good. Higher prices should be considered as harmful since they force consumers to make a bigger monetary sacrifice and reduce their discretionary income. Hence, higher prices should engender negative affect. Following the same logic, lower prices entail a smaller sacrifice and should thus trigger positive affect (Peine et al. 2009).

In addition, an individual's emotions may be directly related to his or her behavior. Lazarus (1991a) proposes that individuals try to cope with the emotions resulting from cognitive appraisal in ways that are consistent with those emotions. As such, emotional coping may involve behavioral actions that are aimed at changing an unfavorable situation for the better or maintaining, enhancing or savoring a favorable situation (Bagozzi et al. 1999; Frijda 1986; Lazarus 1991a). Hence, appraisal theory provides a useful framework for explaining how an individual's affective reaction to a price offer leads to a corresponding behavior. For instance, a lower price should give rise to positive affect, which, in turn, should lead to a behavior that corresponds to that emotion, such as expressing higher purchase intentions. 
Furthermore, consumers' affective reactions may not only be determined by the price information itself, but also by stable individual differences (Kim and Kramer 2006). That is, individual differences may affect the intensity of the emotional experience when processing price information. For instance, imagine consumers who are very frugal by nature. Such consumers may experience a greater negative reaction following a price increase relative to consumers who are less frugal. Consequently, affective reactions may be determined by the interplay of price information and stable individual differences. A conceptual framework summarizing the arguments is depicted in Fig. 1. As the following sections will demonstrate, this framework may prove useful for studying the effects elicited by different MDP profiles.

\subsection{Affective responses to multi-dimensional price profiles}

Everyday experiences (e.g., vacations, hospital stays, or salary payments) develop over time through a series of transient states (Ariely and Carmon 2000; Ariely and Zauberman 2000). When individuals derive summarized evaluations of their experiences, they tend to focus on only a few diagnostic features of the entire profile. More specifically, when outcomes are framed as a sequence of events, individuals prefer to receive the best outcomes at the end. That is, they favor utility levels that improve over time. This is at odds with traditional discounting models built on the notion of the time value of money (Loewenstein and Prelec 1993). Evidence for a negative time preference, i.e. a preference for improving sequences of outcomes, has been found in a variety of domains, such as pain (Ariely 1998), affective episodes (Fredrickson and Kahneman 1993; Varey and Kahneman 1992), TV ads (Baumgartner et al. 1997), service quality (Ariely and Zauberman 2003), and income (Loewenstein and Sicherman 1991).

Yet, these findings have never been applied in the context of MDPs. This is noteworthy because the case for consumers treating equidistantly spaced payments as a sequence is particularly compelling (Ariely and Zauberman 2000). Hence, one may argue that MDPs are also affected by a profile effect. That is, consumers may perceive installments that decrease (increase) over the repayment period as an improving (deteriorating) sequence of outcomes. If this is case, a descending MDP profile (e.g., $40,30,20,10)$ should elicit a greater amount of positive affect than a constant profile

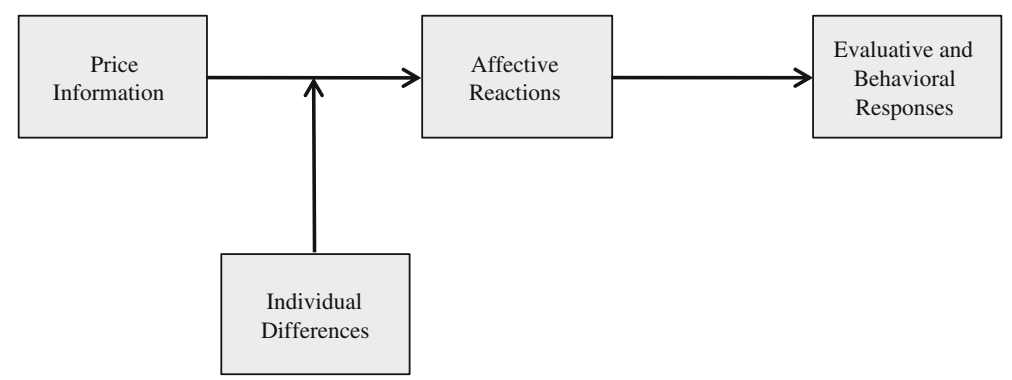

Fig. 1 Conceptual framework of the study 
(e.g., 25, 25, 25, 25), which, in turn, should elicit more positive affect than an ascending profile (e.g., 10, 20, 30, 40). In this respect, Loewenstein and Prelec (1993) offer three theoretical accounts that provide support for this contention: Savoring and dread, adaptation and loss aversion as well as recency effects.

First, with respect to savoring and dread, a descending (ascending) MDP profile expands (shrinks) consumers' discretionary income across time. Descending MDP profiles enable consumers to save the best outcomes (i.e., larger amounts of discretionary income) until the end of the repayment period. Conversely, ascending MDP profiles preclude consumers from getting undesirable outcomes (i.e., larger monthly installments eating into their discretionary income) over with quickly (Loewenstein 1987).

Second, as to adaptation and loss aversion, Loewenstein and Sicherman (1991) have theorized that improving (deteriorating) sequences of outcomes are perceived as a series of gains (losses). Drawing on adaptation-level theory (Helson 1964) and loss aversion (Kahneman and Tversky 1979), the authors argue that consumers adapt to their current level of consumption and seek to realize (avoid) positive (negative) departures from that level. In the current context, descending (ascending) MDP profiles create a series of favorable (unfavorable) backward-looking contrasts. Hence, consumers should perceive monthly installments that decrease (increase) over time as a sequence of gains (losses).

Third, recency effects may also affect the evaluation of MDPs. Varey and Kahneman (1992) have posited that decision-makers naturally adopt a retrospective view in evaluating sequences of outcomes. Similarly, Ross and Simonson (1991) have noted that, after the (anticipated) conclusion of a sequence, the final outcome is most salient. The findings of the latter authors suggest that individuals have a stable preference for happy, or at least hopeful, endings. In the realm of multi-dimensional pricing, decreasing (increasing) monthly installments end on a positive (negative) note, i.e. the lowest (highest) payment in the sequence and should thus trigger greater amounts of positive affect.

In sum, all three theoretical accounts suggest that consumers would show more positive affective responses if they are exposed to descending MDP profiles relative to constant or ascending ones. In addition, appraisal theory also supports the notion that different MDP profiles trigger different affective responses. As outlined in the previous section, appraisal theory posits that events judged as beneficial will give rise to positive emotions, whereas the reverse is true for events that are perceived as harmful (Lazarus 1991a, b; Roseman et al. 1990). From this perspective, a descending profile may be considered as beneficial because it allows consumers to dispose of increasing levels of discretionary income over time (Loewenstein and Sicherman 1991) or to put the mental account for a financed product into the black (Prelec and Loewenstein 1998). These arguments are summarized in the following hypothesis:

H1 A descending MDP profile will lead to more positive affect than a constant MDP profile, which, in turn, will lead to more positive affect than an ascending MDP profile.

As proposed by our general framework, consumers may not only exhibit different amounts of affect in response to different MDP profiles, but may also exhibit 
different evaluative and behavioral responses in order to cope with their emotions. Specifically, different MDP profiles may be associated with different perceptions of value. Consumers assess the value of a particular transaction by comparing what they gain from a purchase (e.g., a high-quality product) with what they need to sacrifice (e.g., money and a loss in discretionary income) (Zeithaml 1988). Given that consumers may feel better after being exposed to a descending (constant) MDP profile relative to a constant (ascending) one, they may also believe that a purchase based on a descending (constant) profile has a greater value than a purchase based on a constant (ascending) profile. Furthermore, consumers should also base their behavioral intentions on their affective reactions (O'Neill and Lambert 2001). That is, consumers should exhibit greater purchase intentions and a greater willingness to spread positive word-of-mouth after being exposed to descending profiles relative to ascending or constant ones. Hence,

H2 A descending (ascending) MDP profile will lead to higher (lower) perceptions of value, higher (lower) purchase intentions, and a higher (lower) willingness to spread positive word-of-mouth than a constant MDP profile.

Furthermore, the arguments outlined above suggest that the extent of positive affect acts as a mediator between different MDP profiles and consumers' evaluative and behavioral responses. That is, the affect elicited by descending MDP profiles should induce higher perceptions of value, higher purchase intentions, and word-ofmouth intentions. Thus,

H3 Positive affect will mediate the effect of different MDP profiles on perceptions of value, purchase intentions, and willingness to spread word-of-mouth.

Lastly, our conceptual framework also proposes that consumers' affective reactions may not only be determined by the price information itself, but also by stable individual differences. However, which individual differences may prove to be particularly relevant in the current context? To this end, it is useful to consider the effects that may be triggered by different MDP profiles. In brief, the hypotheses related to descending, constant, and ascending profiles are based on the assumption that debt is a painful experience and that consumers prefer MDP profiles that allow them to end this painful experience as quickly as possible. If this reasoning is correct, then individual differences that intensify the perception that certain MDP profiles are less painful than others should prove particularly relevant.

Specifically, this research examines the moderating impact of three individual differences, namely debt aversion, financial expectations, and product category knowledge. Whereas category knowledge is a variable that is frequently studied in consumer behavior, debt aversion and financial expectations are variables that have received much less empirical attention. In the current context, however, these variables are of interest since they may affect how consumers process price information. That is, these variables may determine how consumers generally react to price offers, regardless of the particular product (category) being advertised. As such, individual differences that focus on financial decision making may be particularly useful for examining how consumers react to price profiles that are normatively equivalent. Each of these individual differences is discussed in the following sections. 


\subsubsection{Debt aversion}

Recent research has investigated individuals' attitudes toward debt and the consumption behavior caused by those attitudes (Lea et al. 1993, 1995; Livingstone and Lunt 1992). For instance, Lea et al. (1995, p. 682) argue that consumers' attitudes toward debt have changed dramatically in the last decades, "with a shift from general abhorrence of debt to acceptance of credit as a part of a modern consumer society". As such, the extent to which consumers view being in debt as socially acceptable and consider debt as a means to enjoy life to the fullest reliably predicts their levels of indebtedness and debt repayment (Lea et al. 1993; Livingstone and Lunt 1992).

In the present context, different MDP profiles imply different levels of residual debt. After the first payment, the sum of residual debt is necessarily always smaller for descending MDP profiles than for constant and ascending ones, even when all profiles have the same present value. Hence, consumers with an anti-debt attitude should respond more favorably to descending MDP profiles since these allow them to repay larger portions of their debt at the beginning of the repayment period. Ascending profiles, however, may be considered as more stressful since the largest portion of the debt can only repaid at the end of the period.

On the other hand, consumers with a pro-debt attitude may consider being in debt as a normal part of their life and would not consider debt as an aversive experience. If this is the case, then they may be less susceptible to profile effects and may not react differently to different MDP profiles. Put differently, consumers' attitudes toward debt may moderate the effects of different MDP profiles, such that descending profiles will only be evaluated more favorably than constant or ascending ones when consumers have a strong anti-debt attitude. Thus,

H4 Consumers' attitudes toward debt will moderate the effects of different MDP profiles. Specifically, consumers with anti-debt attitudes will react more positively to a descending (constant) profile than to a constant (ascending) profile, whereas consumers with pro-debt attitudes will not show different reactions to different MDP profiles.

\subsubsection{Financial expectations}

Furthermore, consumers' reactions to different price profiles may also be affected by their financial expectations. As such, consumers may harbor different expectations about the development of their income over time (e.g., Brown et al. 2005). Whereas some consumers may have optimistic expectations (i.e., believing that their income will increase), others may feel more doubtful and pessimistic (i.e., believing that their income is more likely to decrease). Similar to debt aversion, financial expectations have been shown to be an important determinant of consumers' financial decisions (Brown et al. 2005; Lunt and Livingstone 1991; van Raaij and Gianotten 1990). For instance, Lunt and Livingstone (1991) found that savings are related to one's optimism about personal economic circumstances.

In the current context, descending (ascending) MDP profiles require consumers to allocate decreasing (increasing) amounts of their income to loan amortization 
across time. Yet, a given MDP profile will be unattractive unless it matches a consumer's (anticipated) income trajectory. Thus, consumers who are financially pessimistic, expecting decreasing income levels, should respond more favorably to descending MDP profiles since these are congruent with their anticipated income trajectory. They may tend, however, to reject ascending profiles since this would imply repaying larger portions of the debt as their income is declining. On the other hand, consumers who are financially optimistic believe that their income will increase over time. Hence, they may find ascending profiles to be less painful and may therefore be less susceptible to the profile effect. In sum, consumers' financial expectations may moderate the effects of different MDP profiles, such that descending profiles will only be evaluated more favorably than constant or ascending ones when consumers are financially pessimistic. Thus,

H5 Consumers' financial expectations will moderate the effects of different MDP profiles. Specifically, consumers who are financially pessimistic will react more positively to a descending (constant) profile than to a constant (ascending) profile, whereas consumers who are financially optimistic will not show different reactions to different MDP profiles.

\subsubsection{Product category knowledge}

Finally, consumers' product category knowledge may also emerge as a significant moderator. In particular, past studies have shown that consumers' product category knowledge affects how they respond to marketing offers (for an overview, see Alba and Hutchinson 1987). Experts possess rich and complex knowledge structures that encourage conceptually driven processing, where new information is linked to existing knowledge (Peracchio and Tybout 1996). Compared to novices, they tend to have established decision criteria in mind and are more likely to systematically acquire new information (Mitchell and Dacin 1996). Novices, lacking complex knowledge structures, engage in data-driven, bottom-up processing strategies and tend to rely on surface characteristics of an object in reaching judgment (Wood and Lynch 2002).

With respect to different MDP profiles, one may argue that experts may be less susceptible to the profile effect. Specifically, given that experts are used to acquiring and processing product-related knowledge very effectively (Mitchell and Dacin 1996), they may realize that different MDP are normatively equivalent as long as the net present value is the same. Hence, they may be less likely to experience positive or negative affect in response to different MDP profiles and should evaluate all profiles similarly. On the other hand, product category novices are less proficient at assessing the relevance of product-related information (Alba and Hutchinson 1987). As a result, they may be more likely to rely on their affective reactions to new price information. Hence, product category knowledge may moderate the effects of different MDP profiles, such that descending profiles will only be evaluated more favorably than constant or ascending ones when consumers are novices rather than experts. In sum,

H6 Consumers' product category knowledge will moderate the effects of different MDP profiles. Specifically, consumers who are novices will react more positively to a 
descending (constant) profile than to a constant (ascending) profile, whereas consumers who are experts will not show different reactions to different MDP profiles.

\section{Empirical investigation}

\subsection{Participants and procedure}

A total of 1,628 consumers visiting the homepage of a European carmaker were asked to participate in an online market research study. Only consumers planning a car purchase within the next 12 months were allowed to take part to ensure sufficient involvement. 93.0\% were male and $85.4 \%$ were between the ages of 21 and 50. Moreover, $41.9 \%$ owned a vehicle of the carmaker conducting the online survey, while $50.5 \%$ had experience with car loans. Self-reported median disposable income was between $€ 3,000$ and $€ 4,999$ per month.

Participants were asked to evaluate a finance offer for a station wagon. In all conditions, participants were provided with an exterior and interior view of the car, its features (e.g., engine and optional equipment), and its list price ( $€$ 37,125). Furthermore, participants were randomly assigned to one of three conditions in a between-subjects design and were exposed to one of three MDP profiles (descending, constant, or ascending). After participants had read the offer, they responded to the dependent variables and were thanked for their participation. As an incentive, participants had the opportunity to enlist in a lottery giving them the chance to win a sports bag.

\subsection{Experimental stimuli}

MDP profile was the independent variable of the study. To probe the profile effect, this variable was manipulated across three levels, namely (1) ascending profile (i.e., an increase in average monthly installment of $€ 200 /$ year), (2) constant profile (i.e., constant installments), and (3) descending profile (i.e., a decrease in average monthly installment of $€ 200$ /year).

The experimental stimuli are provided in Appendix and were designed to rule out possible confounds of the profile effect. First, rational choice theory predicts that consumers prefer MDPs with lower present value to MDPs with higher present value. Thus, at a discount rate of $3.9 \%$ p.a., employing the actual/365 method, all MDP profiles have a present value of $€ 37,125$ ( $\pm .1 \%$ or less due to rounding). In addition, consumers were given the discount rate, the list price, the present value as well as the information that the latter two are identical to reduce the confounding influence of perceived expensiveness. Second, the velocity at which outcomes change over time is known to affect summarized evaluations of extended experiences (Hsee and Abelson 1991). Thus, the rate at which average monthly installments changed was identical in magnitude (i.e., $\pm € 200$ /year). Third, consumers might infer the appeal of a non-flat MDP profile from the number of changes in monthly installments. Accordingly, both the ascending and descending MDP profile featured four different levels of monthly installments that each lasted for 12 months, implying three jumps and plunges, respectively. 


\subsection{Measures}

The level of positive affect was measured with four-seven-point items ("not optimistic/optimistic", "not encouraged/encouraged", "not hopeful/hopeful", "not relieved/relieved", $\alpha=.95)$ from Richins (1997). All items in the study used sevenpoint scales. Perceived value was measured with three items ("The value of this car is very high", "given its list price, this car is a good deal", "at the price shown, this car is very economical", $\alpha=.81$ ) adapted from Dodds et al. (1991). Purchase intentions were measured with three items ("The likelihood of purchasing this car is very high", "at the price shown, I would consider buying this car", "my willingness to buy this car is very high", $\alpha=.96$ ) based on Dodds et al. (1991). Willingness to spread positive word-of-mouth was gauged employing three items ("I will say positive things about the offer for this car to other people", "I will recommend the offer for this car to someone who seeks my advice", "I will encourage friends and relatives to consider the offer for this car when planning to buy a new automobile", $\alpha=.94$ ) adapted from Zeithaml et al. (1996).

Finally, the proposed moderators were gauged with items adapted from previous research. Participants attitudes toward debt were measured with thirteen items ( $\alpha=.87$ ) from Lea et al. (1995); financial expectations were measured with three items $(\alpha=.89)$ adapted from Brown et al. (2005); product category knowledge was measured with seven items $(\alpha=.87)$ adapted from Srinivasan and Ratchford (1991).

\section{Results}

\subsection{Testing group homogeneity}

Before testing any of the hypotheses, we ascertained whether the three experimental groups were homogenous with respect to a number of exogenous variables. Several contingency analyses revealed that the experimental groups did not differ in terms of gender $(p>.64)$, experience with car loans $(p>.24)$, and ownership of the manufacturer's vehicles $(p>.43)$. In addition, several ANOVAs showed that there were no differences in terms of age $(p>.89)$ and income $(p>.63)$. Furthermore, we also tested whether the groups differed with respect to the three individual differences that were proposed as moderators. As expected, several ANOVAs showed that the three groups did not differ in terms of debt aversion $(p>.79)$, financial expectations $(p>.12)$, and product category knowledge $(p>.82)$. Hence, we may conclude that the experimental groups are relatively homogenous.

\subsection{Positive affect}

To examine hypothesis 1, a single-factor (MDP profile: descending, constant, ascending) ANOVA was conducted. This analysis revealed a main effect for the kind of MDP profile on positive affect $(F(1,1625)=24.99, p<.001)$. Following this, we compared the groups using LSD procedures. Testing the profile effect involves a comparison between (1) the descending and the constant condition as 
well as (2) the constant and the ascending condition. As expected, a descending profile induced more positive affect than a constant one $\left(\mathrm{M}_{\text {desc }}=3.31, \mathrm{M}_{\text {const }}=\right.$ $3.11, p<.03)$, which, in turn, triggered more affect than an ascending profile $\left(\mathrm{M}_{\mathrm{const}}=3.11, \mathrm{M}_{\mathrm{asc}}=2.71, p<.001\right)$. Hence, hypothesis 1 is supported.

\subsection{Perceptions of value, purchase intentions, and word-of-mouth intentions}

To examine hypothesis 2, a one-factor (MDP profile: descending, constant, ascending) MANOVA was conducted. This analysis revealed a significant main effect for the kind of MDP profile (Wilk's lambda $=.96, p<.001$ ). More specifically, this effect was also confirmed at the univariate level for perceptions of value $(F(1,1625)=3.62, p<.03)$, purchase intentions $(F(1,1625)=17.55$, $p<.001)$, and word-of-mouth intentions $(F(1,1625)=22.96, p<.001)$. As expected, LSD comparisons showed that a descending profile led to higher perceptions of value $\left(\mathrm{M}_{\mathrm{desc}}=4.35, \mathrm{M}_{\text {const }}=4.14, p<.01\right)$, higher purchase intentions $\left(\mathrm{M}_{\mathrm{desc}}=2.82, \mathrm{M}_{\text {const }}=2.60, p<.05\right)$, and a higher willingness to spread positive word-of-mouth $\left(\mathrm{M}_{\mathrm{desc}}=4.08, \mathrm{M}_{\text {const }}=3.82, p<.03\right)$ than a constant profile, providing support for hypothesis 2 . Similarly, participants that had been exposed to a constant profile reported higher purchase intentions $\left(\mathrm{M}_{\text {const }}=\right.$ $\left.2.60, \mathrm{M}_{\mathrm{asc}}=2.21, p<.001\right)$ and higher word-of-mouth intentions $\left(\mathrm{M}_{\text {const }}=3.82\right.$, $\left.\mathrm{M}_{\text {asc }}=3.33, p<.001\right)$ than those that had been exposed to an ascending profile. Perceptions of value, however, did not differ significantly between these conditions $\left(\mathrm{M}_{\text {const }}=4.14, \mathrm{M}_{\mathrm{asc}}=4.26, p>.13\right)$. Hence, hypothesis 1 was fully confirmed for purchase intentions and word-of-mouth intentions (see also Fig. 2), yet only partially confirmed for perceptions of value. This issue is addressed in the final discussion. Mean values for the dependent variables appear in Table 1.

\subsection{Mediational analyses}

To examine whether positive affect mediated the impact of different MDPs on the dependent variables, we followed the recommendations from Baron and Kenny (1986). In a first step, we conducted a mediation analysis for the descending and the constant conditions. Firstly, the kind of MDP profile (dummy variable: constant $=0$, descending $=1$ ) had a significant impact on the dependent variables $\left(\mathrm{b}_{\text {value }}=.08, p<.01 ; \mathrm{b}_{\text {pur_int }}=.06, p<.05 ; \mathrm{b}_{\text {wom }}=.07, p<.03\right)$. Secondly, the independent variable was also significantly related to the level of positive affect $(b=.07, p<.03)$. Thirdly, positive affect was also a significant predictor of the dependent variables $\left(\mathrm{b}_{\text {value }}=.42, p<.001 ; \mathrm{b}_{\text {pur_int }}=.64, p<.001 ; \mathrm{b}_{\text {wom }}=.66\right.$, $p<.01)$. Lastly, when both the independent variable and the mediator were included in the regression model, affect remained a significant predictor $\left(b_{\text {value }}=\right.$ $\left..41, p<.001 ; \mathrm{b}_{\text {pur_int }}=.64, p<.03 ; \mathrm{b}_{\text {wom }}=.66, p<.01\right)$, whereas the effect of MDP profiles was eliminated $\left(b_{\text {value }}=.06, p>.06 ; b_{\text {pur_int }}=.02, p>.48\right.$; $\left.\mathrm{b}_{\mathrm{wom}}=-.02, p>.34\right)$. A Sobel test of mediation was significant for all three variables $\left(\mathrm{z}_{\mathrm{value}}=2.23, p<.03 ; \mathrm{z}_{\text {pur_int }}=2.14, p<.03 ; \mathrm{z}_{\mathrm{wom}}=2.25, p<.02\right.$; see Baron and Kenny (1986)). 


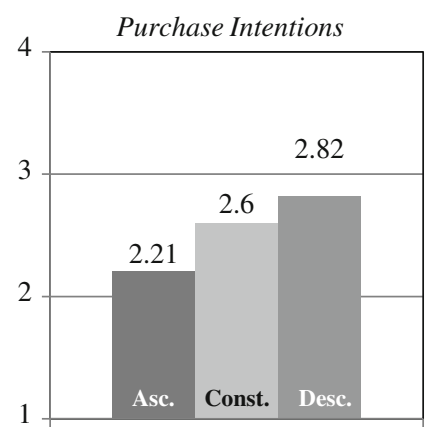

Development of Payment Pattern

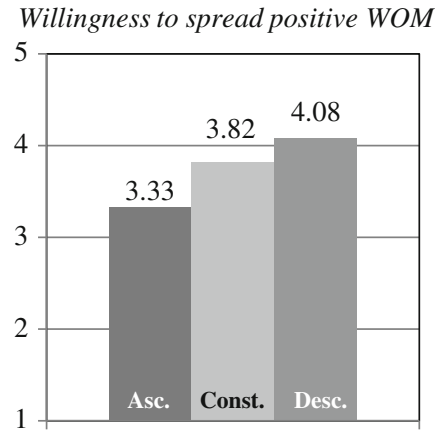

Development of Payment Pattern

Fig. 2 The impact of price profiles on purchase intentions and word-of-mouth

Table 1 Means for the dependent variables

\begin{tabular}{llll}
\hline & Ascending profile & Constant profile & Descending profile \\
\hline Perceptions of value & $4.26^{\mathrm{a}}(1.27)$ & $4.14^{\mathrm{a}}(1.24)$ & $4.35^{\mathrm{b}}(1.23)$ \\
Purchase intentions & $2.21^{\mathrm{a}}(1.65)$ & $2.60^{\mathrm{b}}(1.71)$ & $2.82^{\mathrm{c}}(1.84)$ \\
Positive word-of-mouth & $3.33^{\mathrm{a}}(1.92)$ & $3.82^{\mathrm{b}}(1.86)$ & $4.08^{\mathrm{c}}(1.92)$ \\
Positive affect & $2.71^{\mathrm{a}}(1.41)$ & $3.11^{\mathrm{b}}(1.46)$ & $3.31^{\mathrm{c}}(1.51)$ \\
\hline
\end{tabular}

All items were measured with 7-point scales. Numbers in parentheses indicate standard deviations. Mean values across the rows for a variable with different superscripts $\mathrm{a}, \mathrm{b}$, and $\mathrm{c}$ are different at $p<.05$

In a second step, we conducted a second mediation analysis, comparing the constant condition with the ascending condition (dummy variable: ascending $=0$, constant $=1$ ). Firstly, the kind of MDP profile was positively related to two of the dependent variables $\left(\mathrm{b}_{\text {pur_int }}=.12, p<.001 ; \mathrm{b}_{\text {wom }}=.13, p<.001\right)$ and, secondly, to the level of positive affect $(b=.14, p<.001)$. Thirdly, affect was also associated with two of the dependent variables $\left(b_{\text {pur_int }}=.67, \quad p<.001\right.$; $\left.\mathrm{b}_{\text {wom }}=.66, p<.001\right)$. Lastly, when both the independent variable and the mediator were included in the regression model, affect remained a significant predictor $\left(b_{\text {pur_int }}=.67, p<.001 ; b_{\text {wom }}=.65, p<.001\right)$, whereas the effect of MDP profiles was eliminated $\left(b_{\text {pur_int }}=.02, p>.33 ; b_{\text {wom }}=.04, p>.08\right)$. Two Sobel tests confirmed the significance of the mediation $\left(\mathrm{z}_{\text {pur_int }}=4.48, p<.001\right.$; $\left.\mathrm{z}_{\mathrm{wom}}=4.47, p<.001\right)$. The hypothesized mediation was not supported, however, for perceptions of value since this variable was not affected significantly by constant or ascending MDP profiles $(b=-.05, p>.13)$.

\subsection{Moderating effects of debt aversion}

To test hypothesis 4, we conducted several OLS-regression analyses. In this regression, we mean-centered the debt attitude scores and included them as a continuous predictor variable in the model. Moreover, we specified two dummy variables for the kind of MDP profile (i.e., one dummy comparing the constant 
condition to the descending condition, one dummy comparing the constant condition to the ascending condition) as well as two terms for the interactions between debt attitudes and the dummy variables. In a next step, we regressed the four dependent measures on all of these variables (see Table 2).

These analyses revealed significant effects for the dummy comparing the constant to the descending condition as well as the dummy comparing the constant to the ascending condition for all four variables. However, the hypothesized interaction effects between the two dummy variables and the debt attitude scores failed to reach significance (see Table 2).

To examine these results in greater depth, we conducted several spotlight analyses (Fitzsimons 2008). In a spotlight analysis, the researcher can focus the "spotlight" on a particular level of a continuous independent variable by shifting the mean of this variable up or down (i.e., by adding a constant to all of the responses). In the current case, we conducted separate spotlight analyses for participants with anti-debt attitudes (i.e., one standard deviation above the mean) and for participants with pro-debt attitudes (i.e., one standard deviation below the mean). The purpose of these analyses was to examine the impact of different MDP profiles at different levels of debt attitudes.

\subsubsection{Participants with anti-debt attitudes}

First, we conducted a spotlight analysis for participants with strong anti-debt attitudes (i.e., one standard deviation above the mean). This analysis yielded a significant main effect for the dummy comparing the constant to the descending condition for three of the four dependent variables (Affect: $b=.08, p<.05$; Value: $b=.09, p<.04$; Purchase intentions: $b=.08, p<.05)$. The effect for word-ofmouth intentions was only marginally significant $(b=.07, p<.09)$. Consistent with expectations, participants reported higher levels of positive affect $\left(\mathrm{M}_{\text {desc }}=\right.$ $\left.3.26, \mathrm{M}_{\text {const }}=3.01\right)$, higher perceptions of value $\left(\mathrm{M}_{\mathrm{desc}}=4.24, \mathrm{M}_{\text {const }}=4.02\right)$, higher purchase intentions $\left(\mathrm{M}_{\mathrm{desc}}=2.63, \mathrm{M}_{\text {const }}=2.34\right)$, and higher intentions to spread word-of-mouth $\left(\mathrm{M}_{\text {desc }}=4.05, \mathrm{M}_{\text {const }}=3.76\right)$ when they had been exposed to a descending profile compared to a constant profile.

Furthermore, the analysis also revealed a positive main effect for the dummy comparing the constant to the ascending condition for three dependent variables (Affect: $b=-.15, p<.01$; Purchase intentions: $b=-.10, p<.02$; WOM: $b=$ $-.15, p<.01)$. As expected, a constant profile led to more positive affect $\left(\mathrm{M}_{\text {const }}=3.01, \mathrm{M}_{\mathrm{asc}}=2.55\right)$, higher purchase intentions $\left(\mathrm{M}_{\mathrm{const}}=2.34, \mathrm{M}_{\mathrm{asc}}=\right.$ $1.98)$, and higher word-of-mouth intentions than an ascending profile $\left(\mathrm{M}_{\text {const }}=\right.$ $\left.3.76, M_{\text {asc }}=3.16\right)$. Perceptions of value, however, did not differ $\left(M_{\text {const }}=4.02\right.$, $\mathrm{M}_{\text {asc }}=4.12, b=.04, p>.35$ ) Overall, these results provide support for hypothesis 4 by showing that participants with strong anti-debt attitudes are very sensitive to how different MDP profiles unfold over time.

\subsubsection{Participants with pro-debt attitudes}

Next, we conducted a spotlight analysis for participants with pro-debt attitudes (i.e., one standard deviation below the mean). As expected, this analysis revealed an 
Table 2 Results of the spotlight analyses

\begin{tabular}{|c|c|c|c|c|c|c|}
\hline & \multicolumn{2}{|c|}{ Mean-centered scores } & \multicolumn{2}{|c|}{$\begin{array}{l}\text { Anti-debt participants } \\
(+1 \text { SD })\end{array}$} & \multicolumn{2}{|c|}{$\begin{array}{l}\text { Pro-debt participants } \\
(-1 \mathrm{SD})\end{array}$} \\
\hline & $\begin{array}{l}\text { Standard } \\
\text { estimate }\end{array}$ & $t$ value & $\begin{array}{l}\text { Standard } \\
\text { estimate }\end{array}$ & $t$ value & $\begin{array}{l}\text { Standard } \\
\text { estimate }\end{array}$ & $t$ value \\
\hline \multicolumn{7}{|l|}{ Debt attitudes } \\
\hline Affect & -.063 & -1.428 & -.063 & -1.428 & -.063 & -1.428 \\
\hline Value & -.097 & $-2.175^{*}$ & -.097 & $-2.175^{*}$ & -.097 & $-2.175^{*}$ \\
\hline P. Intentions & -.148 & $-3.372 * *$ & -.148 & $-3.372 * *$ & -.148 & $-3.372 * *$ \\
\hline WOM & -.030 & -.680 & -.030 & -.680 & -.030 & -.680 \\
\hline \multicolumn{7}{|c|}{ Dummy 1 (Cons $>$ Desc) } \\
\hline Affect & .067 & $2.326^{*}$ & .078 & $1.962 *$ & .055 & 1.356 \\
\hline Value & .080 & $2.761 * *$ & .085 & $2.063^{*}$ & .074 & 1.829 \\
\hline P. Intentions & .061 & $2.140 *$ & .080 & $1.969 *$ & .043 & 1.046 \\
\hline WOM & .064 & $2.210^{*}$ & .070 & 1.703 & .058 & 1.411 \\
\hline \multicolumn{7}{|c|}{ Dummy 2 (Cons $>$ Asc $)$} \\
\hline Affect & -.128 & $-4.464 * *$ & -.152 & $-3.722 * *$ & -.104 & $-2.604 * *$ \\
\hline Value & .045 & 1.542 & .038 & .928 & .051 & 1.261 \\
\hline P. Intentions & -.104 & $-3.631 * *$ & -.096 & $-2.352^{*}$ & -.113 & $-2.802 * *$ \\
\hline WOM & -.123 & $-4.280 * *$ & -.150 & $-3.666^{* *}$ & -.097 & $-2.398^{*}$ \\
\hline \multicolumn{7}{|c|}{ Attitudes $\times$ Dummy 1} \\
\hline Affect & .014 & .399 & .018 & .399 & .018 & .399 \\
\hline Value & .006 & .165 & .008 & .165 & .008 & .165 \\
\hline P. Intentions & .023 & .650 & .029 & .650 & .030 & .650 \\
\hline WOM & .007 & .206 & .010 & .206 & .009 & .206 \\
\hline \multicolumn{7}{|c|}{ Attitudes $\times$ Dummy 2} \\
\hline Affect & -.029 & -.820 & -.038 & -.820 & -.038 & -.820 \\
\hline Value & -.008 & -.227 & -.011 & -.227 & -.010 & -.227 \\
\hline P. Intentions & .011 & .297 & .014 & .297 & .014 & .297 \\
\hline WOM & -.033 & -.925 & -.043 & -.925 & -.042 & -.925 \\
\hline
\end{tabular}

$* p<.05, * * p<.01$

insignificant main effect for the dummy comparing the constant to the descending condition for all four dependent variables (Affect: $b=.06, p>.17$; Value: $b=.07, p>.07$; Purchase intentions: $b=.04, p>.29$; WOM: $b=.06, p>.15)$. That is, participants revealed very similar levels of positive affect $\left(\mathrm{M}_{\text {desc }}=3.37\right.$, $\left.\mathrm{M}_{\text {const }}=3.20\right)$, value perceptions $\left(\mathrm{M}_{\mathrm{desc}}=4.46, \mathrm{M}_{\text {const }}=4.26\right)$, purchase intentions $\left(\mathrm{M}_{\mathrm{desc}}=3.01, \mathrm{M}_{\text {const }}=2.85\right)$, and word-of-mouth intentions $\left(\mathrm{M}_{\mathrm{desc}}=4.11\right.$, $\mathrm{M}_{\text {const }}=3.88$ ) across both kinds of profiles. Put differently, they did not seem to care whether the payments were constant or decreased over time.

Contrary to our expectations, however, the analysis also revealed a significant main effect for the dummy comparing the constant to the ascending condition for three out of the four dependent variables (Affect: $b=-.10, p<.01$; Purchase intentions: $b=-.11, p<.01$; WOM: $b=-.10, p<.02)$. That is, a constant 
profile led to higher levels of positive affect $\left(\mathrm{M}_{\text {const }}=3.20, \mathrm{M}_{\mathrm{asc}}=2.87\right)$, higher purchase intentions $\left(\mathrm{M}_{\text {const }}=2.85, \mathrm{M}_{\mathrm{asc}}=2.44\right)$, and higher word-of-mouth intentions $\left(\mathrm{M}_{\mathrm{const}}=3.88, \mathrm{M}_{\mathrm{asc}}=3.49\right)$ than an ascending profile. Perceptions of value did not differ between the two conditions $\left(M_{\text {const }}=4.26, M_{\text {asc }}=4.40\right.$, $b=.05, p>.20$ ). Hence, there is only partial support for hypothesis 4. Arguably, ascending profiles seemed so disadvantageous that even participants with pro-debt attitudes disliked them.

\subsection{Moderating effects of financial expectations}

To test hypothesis 5, we followed the same procedure as outlined above. As such, the regression analyses revealed a number of significant main effects for financial expectations and the two dummy variables. However, the interaction between financial expectations and the constant/ascending dummy (Affect: $b=.03, p>.47$; Value: $b=-.01, p>.82$; Intentions: $b=-.01, p>.96$; WOM: $b=-.03$, $p>.38)$ as well as the interaction between expectations and the constant/ descending dummy (Affect: $b=.05, p>.19$; Value: $b=.05, p>.12$; Intentions: $b=-.01, p>.68$; WOM: $b=.01, p>.75)$ did not reach significance. Furthermore, two spotlight analyses conducted at higher (plus one standard deviation) and lower (minus one standard deviation) levels of financial expectations did not reveal any of the postulated effects. Hence, H5 is not confirmed.

\subsection{Moderating effects of product category knowledge}

Finally, we tested if knowledge moderates the effect of MDP profiles. These analyses showed significant main effects for the two dummy variables. However, the interaction between knowledge and the constant/ascending dummy (Affect: $b=.01, p>.87$; Value: $b=-.02, p>.65$; Intentions: $b=.02, p>.60$; WOM: $b=-.01, p>.92)$ as well as the interaction between knowledge and the constant/ descending dummy (Affect: $b=.02, p>.52$; Value: $b=.01, p>.85$; Intentions: $b=.03, p>.38$; WOM: $b=.04, p>.30$ ) were not significant. In addition, two spotlight analyses conducted at higher (plus one standard deviation) and lower (minus one standard deviation) levels of knowledge did not provide support for any of the postulated effects. Hence, H6 is not confirmed.

\section{Discussion}

The goal of this research was to examine consumer preferences for different MDP profiles. The results of a field experiment demonstrate that consumers respond differently to profiles with different payment patterns, even when all profiles have the same present value. That is, MDP profiles with descending monthly installments elicited more positive affect and were evaluated more favorably than profiles with constant installments, which, in turn, elicited more positive affect and were evaluated more favorably than profiles with ascending installments. 
However, it must be noted that the predicted relationships were not fully confirmed for one of the dependent variables, namely perceptions of value. This may seem less noteworthy when considering that we explicitly communicated the net present value of the finance offer to participants (which was the same across all conditions, see Appendix). In light of this, it seems even more surprising that participants were affected by different MDP profiles. Even though participants are likely to have been aware that a particular price profile did not change the objective value of the offer, they could not help experiencing greater levels of positive affect in response to a descending profile than to a constant or an ascending one. Subsequently, they relied on their affect to judge their likelihood of buying or recommending the offer.

\subsection{Theoretical and managerial contributions}

Overall, the study makes several theoretical contributions to the literature. Firstly, the findings contribute to pricing research by showing that consumers prefer descending MDP profiles over constant and ascending ones, even if all profiles are normatively equivalent. More specifically, our study also sheds light on the underlying process and shows that different MDP profiles elicit different amounts of positive affect, which, in turn, lead to different evaluative consequences. Similar results have been found in such diverse domains as pain (Ariely 1998), affective episodes (Fredrickson and Kahneman 1993), TV ads (Baumgartner et al. 1997), service quality (Ariely and Zauberman 2003), and social behavior (Loewenstein and Prelec 1991). All the same, the current study extends these findings by demonstrating that individuals may also be susceptible to profile effects in domains that have been examined from a predominantly cognitive perspective-namely consumers' reactions to price offers.

Secondly, the results also contribute to the growing body of research on the role of price affect. This research has argued that consumers' affective responses to price information may be an important determinant of their evaluations and purchase decisions. Mostly, studies in this area have focused on stationary prices or real, substantive changes in price information such as price increases and price discounts (e.g., Honea and Dahl 2005; O’Neill and Lambert 2001; Peine et al. 2009). However, appraisal theory-the core theoretical tenet of our study-posits that emotions result from the cognitive appraisal of an event rather than from the event itself. Put differently, the normative implications of price information may be less relevant than consumers' subjective assessments of that information. In line with this reasoning, our study shows that consumers' affective responses may determine their preferences for different MDP profiles-even when all profiles have the same net value and are normatively equivalent. In doing so, the results extend existing research and attest to the importance of affect in consumers' price evaluations.

Thirdly, this research attempted to identify individual differences that moderate the impact of different MDP profiles. Since debt is usually considered as an aversive experience (Prelec and Loewenstein 1998), consumers with strong anti-debt attitudes should be affected more strongly by MDP profiles that allow them to escape from such an experience at a faster rate than consumers with pro-debt attitudes. This notion, however, was only partially confirmed. Consistent with expectations, 
consumers with anti-debt attitudes were affected more strongly by a descending profile (compared to a constant profile) than consumers with pro-debt attitudes. However, debt attitudes did not affect how consumers evaluated a constant profile (compared to an ascending profile). This may be due to the fact that ascending profiles are so unacceptable that even consumers with low anti-debt attitudes disapprove of them. Contrary to our expectations, consumers' financial expectations as well as product category knowledge did not emerge as significant moderators of the profile effect. Interestingly, these results may indicate that profile effects can also be observed for consumers who are highly knowledgeable about a product category and who are fairly optimistic about the development of their income.

Regarding managerial implications, the results of this research suggest that making use of different MDP profiles may lead to beneficial consequences. Firstly, offering descending rather than constant MDP profiles provides sellers with an opportunity for increasing both volumes and sales. Yet, offering an ascending MDP profile-e.g., in order to entice consumers with low initial installments-will likely have an opposite effect. This implies that "buy now, pay later"-strategies may backfire on sellers. Secondly, different MDP profiles with the same present value have different cash flow implications. Descending profiles entail larger cash flows at the beginning of a repayment period, allowing companies to reinvest larger amounts of cash at earlier points in time. Assuming that a company's reinvestment rate exceeds its discount rate, descending profiles will yield higher discounted cash flows than constant or ascending ones. In sum, there is little reason to believe that descending MDP profiles would harm a seller.

\subsection{Limitations and future research suggestions}

The current research, however, suffers from some limitations that need to be noted. Firstly, the study was set in the automotive sector and asked consumers to evaluate a hypothetical finance offer. Thus, one may argue that the decision context was a relatively specific one and that participants did not make any choices with real financial implications. Future studies may want to address these issues by examining the robustness of the profile effect in more realistic, everyday situations and relying on behavioral data instead of subjective evaluations.

Secondly, even though we took great care to communicate the net present value of all offers to participants (e.g., by featuring graphical displays, by telling participants that the list price and the net value were equivalent, etc.), it seems possible that they may have come to a different conclusion. Put differently, participants may have believed that, say, a descending profile was a financially better deal than an ascending profile. In fact, the results demonstrate that consumers' subjective perceptions are crucial in determining the effects of different MDP profiles. Hence, it seems advisable to address this issue more explicitly in future research, thereby ensuring that our results are caused by shifts in affective responses and not by cognitive miscalculations of an offer's value. One way to address this issue may consist in using a within-subjects design in which consumers can freely choose between different MDP profiles. In this case, consumers should be even more aware that different profiles are normatively equivalent. 
Thirdly, another limitation of our research is that we did not measure participants' level of involvement with cars in general or with a potential purchase process before exposing them to the experimental treatments. This may have affected the interpretability and generalizability of our results in two different ways. For one, we cannot determine whether there was homogeneity within and between the experimental groups with respect to involvement prior to the start of the study. In addition, we were not able to examine if or how consumer reactions to MDP profiles may vary across different product involvement levels. Since involvement is one of the most central constructs in consumer behavior, it would be interesting to examine the role of product involvement. As such, involvement may affect the effects developed in this research in two different ways. On the one hand, low-involvement consumers may be more susceptible to the profile effect because they are less motivated to process any price information in great depth and may be more likely to rely on their affect. On the other hand, it also seems possible that different MDP profiles will not engender any strong affective reactions in low-involvement consumers because these consumers do not care enough about the purchase decision. Hence, they may be less susceptible to the effect triggered by descending profiles.

Future research may also address the role of different temporal perspectives in the context of multi-dimensional pricing. According to construal level theory (CLT), temporal distance changes responses to future events by changing the way people mentally construe those events (Liberman and Trope 1998; Trope and Liberman 2003). On the one hand, individuals construe temporally near events in terms of low-level and concrete features. Consequently, the evaluation of those events is likely to be based on low-level, contextual aspects. On the other hand, individuals construe temporally distant situations in terms of high-level and abstract features. Correspondingly, the evaluation of temporally distant situations is likely to be based on high-level aspects. Arguably, the sequence of a MDP profile is a lowlevel feature, whereas the profile's net value is a high-level feature. If this is the case, consumers may be more susceptible to profile effects when the repayment period starts in their immediate future or when all installments need to paid in a relatively short period of time. They may, however, put less emphasis on a profile's sequence when the repayment period only begins in their more distant future or when the installments stretch across a relatively long period of time.

Gaining further insights into how sequences of payments are evaluated will enable both buyers and sellers to benefit from marketing offers that "follow a pattern that matches [consumers'] preferences for how real-life experiences should turn out" (Baumgartner et al. 1997). The present paper hopes to spur research along these lines.

Acknowledgments The authors would like to thank two anonymous reviewers and the editor for their helpful comments and suggestions.

\section{Appendix}

See Fig. 3. 

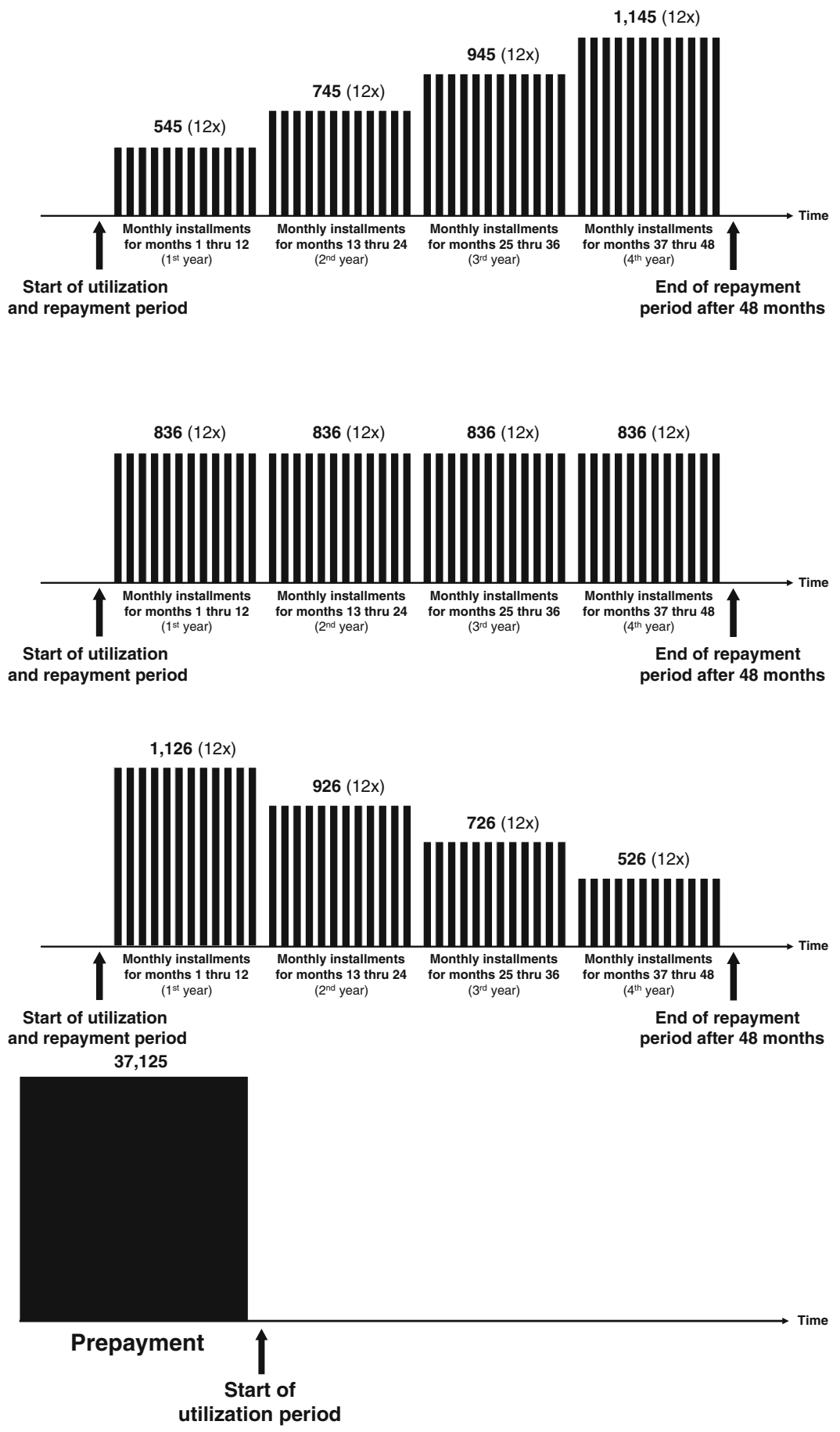

Fig. 3 Experimental stimuli 


\section{References}

Alba JW, Hutchinson JW (1987) Dimensions of consumer expertise. J Cons Res 13(4):411-454

Andrade EB (2005) Behavioral consequences of affect: combining evaluative and regulatory mechanisms. J Cons Res 32(3):355-362

Ariely D (1998) Combining experiences over time: the effects of duration, intensity changes and on-line measurements on retrospective pain evaluations. J Behav Decis Mak 11(1):19-45

Ariely D, Carmon Z (2000) Gestalt characteristics of experiences: the defining features of summarized events. J Behav Decis Mak 13(2):191-201

Ariely D, Zauberman G (2000) On the making of an experience: the effects of breaking and combining experiences on their overall evaluation. J Behav Decis Mak 13(2):219-232

Ariely D, Zauberman G (2003) Differential partitioning of extended experiences. Org Behav Hum Decis Process 91(2):128-139

Bagozzi RP, Gopinath M, Nyer P (1999) The role of emotions in marketing. J Mark 27(2):184-206

Baron RM, Kenny DA (1986) The moderator-mediator variable distinction in social psychological research: conceptual, strategic, and statistical considerations. J Pers Soc Psychol 51(6):1173-1182

Baumgartner H, Sujan M, Padgett D (1997) Patterns of affective reactions to advertisements: the integration of moment-to-moment responses into overall judgments. J Mark Res 34(2):219-232

Brown S, Garino G, Taylor K, Price SW (2005) Debt and financial expectations: an individual- and household-level analysis. Econ Inquiry 43(1):100-120

Dodds WB, Monroe DG, Grewal D (1991) Effects of price, brand, and store information on buyers' product evaluations. J Mark Res 28(3):307-319

Estelami H (1997) Consumer perceptions of multi-dimensional prices. Adv Cons Res 24(1):392-399

Fitzsimons GJ (2008) Death to dichotomizing. J Con Res 35(1):5-8

Fredrickson BL, Kahneman D (1993) Duration neglect in retrospective evaluations of affective episodes. J Pers Soc Psychol 65(1):45-55

Frijda NH (1986) The emotions. Cambridge University Press, New York

Gourville JT (1998) Pennies-a-day: the effect of temporal reframing on transaction evaluation. J Cons Res 24(4):395-408

Helson H (1964) Adaptation-level theory: an experimental and systematic approach to behavior. Harper \& Row, New York

Honea H, Dahl DW (2005) The promotion affect scale: defining the affective dimensions of promotion. J Bus Res 58(4):543-551

Hsee CK, Abelson RP (1991) Velocity relation: satisfaction as a function of the first derivative of outcome over time. J Pers Soc Psychol 60(3):341-346

Kahneman D, Tversky A (1979) Prospect theory: an analysis of decision under risk. Econometrica 47(2):263-291

Kahneman D, Slovic P, Tversky A (1982) Judgment under uncertainty: heuristics and biases. Cambridge University Press, New York

Kim MH, Kramer T (2006) The moderating effects of need for cognition and cognitive effort on responses to multi-dimensional prices. Mark Let 17(3):193-203

Ladhari R (2007) The effect of consumption emotions on satisfaction and word-of-mouth communications. Psychol Mark 24(12):1085-1108

Lazarus RS (1991a) Emotion and adaptation. Oxford University Press, New York

Lazarus RS (1991b) Progress on a cognitive-motivational-relational theory of emotion. Amer Psychol 46(8):819-834

Lea SEG, Webley P, Levine RM (1993) The economic psychology of consumer debt. J Econ Psychol 14(1):85-119

Lea SEG, Webley P, Walker CM (1995) Psychological factors in consumer debt: money management, economic socialization, and credit use. J Econ Psychol 16(4):681-701

Liberman N, Trope Y (1998) The role of feasibility and desirability considerations in near and distant future decisions: a test of temporal construal theory. J Pers Soc Psychol 75(1):5-18

Livingstone S, Lunt PK (1992) Predicting personal debt and debt repayment: psychological, social and economic determinants. J Econ Psychol 13(1):111-134

Loewenstein G (1987) Anticipation and the valuation of delayed consumption. Econ J 97(387):666-684

Loewenstein G, Prelec D (1991) Negative time preference. Amer Econ Rev 81(2):347-352

Loewenstein G, Prelec D (1993) Preferences for sequences of outcomes. Psychol Rev 100(1):91-108 
Loewenstein G, Sicherman N (1991) Do workers prefer increasing wage profiles? J Lab Econ 9(1):67-84

Lunt PK, Livingstone SM (1991) Psychological, social, and economic determinants of saving: comparing recurrent and total savings. J Econ Psychol 12(4):621-641

Mitchell AA, Dacin PA (1996) The assessment of alternative measures of consumer expertise. J Cons Res 23(3):219-238

Morwitz VG, Greenleaf EA, Johnson EJ (1998) Divide and prosper: consumers' reactions to partitioned prices. J Mark Res 35(4):453-463

O'Neill RM, Lambert DR (2001) The emotional side of price. Psychol Mark 18(3):217-237

Peine K, Heitmann M, Herrmann A (2009) Getting a feel for price affect: a conceptual framework and empirical investigation of consumers' emotional responses to price information. Psychol Mark 26(1):39-66

Peracchio LA, Tybout A (1996) The moderating role of prior knowledge in schema-based product evaluation. J Cons Res 23(3):177-192

Prelec D, Loewenstein G (1998) The red and the black: mental accounting of savings and debt. Mark Sci 17(1):4-28

Richins ML (1997) Measuring emotions in the consumption experience. J Cons Res 24(2):127-146

Roseman IJ, Spindel MS, Jose PE (1990) Appraisals of emotion-eliciting events: testing a theory of discrete emotions. J Pers Soc Psychol 59(5):899-915

Ross WT, Simonson I (1991) Evaluations of pairs of experiences: a preference for happy endings. J Behav Decis Mak 4(4):273-282

Srinivasan N, Ratchford BT (1991) An empirical test of an external search model for automobiles. J Cons Res 18(2):233-242

Suri R, Manchanda RV, Kohli C (2002) Comparing fixed price and discounted price strategies: the role of affect on evaluations. J Prod Brand Manag 11(3):160-171

Trope Y, Liberman N (2003) Temporal construal. Psychol Rev 110(3):403-421

van Raaij WF, Gianotten HJ (1990) Consumer confidence, expenditure, saving, and credit. J Econ Psychol 11(2):269-290

Varey CA, Kahneman D (1992) Experiences extended across time: evaluation of moments and episodes. J Behav Decis Mak 5(3):169-185

Wood SL, Lynch JG (2002) Prior knowledge and complacency in new product learning. J Cons Res 29(3):416-426

Zeithaml VA (1988) Consumer perceptions of price, quality, and value: a means-end model and synthesis of evidence. J Mark 52(3):2-22

Zeithaml VA, Berry LL, Parasuraman A (1996) The behavioral consequences of service quality. J Mark 60(2):31-46 